\title{
Probation worker responses to turbulent conditions: constructing identity in a tainted occupation
}

\section{Anne Worrall and Rob C Mawby}

\section{Introduction}

Despite governmental attempts to eradicate it from criminal justice vocabulary in England and Wales (Worrall 1998; 2008), the concept of 'probation' has proved remarkably resilient and has, in recent years, come to signify subversion of the dominant penal discourse of 'offender management' ${ }^{1}$. It has become an 'imaginary penality' (Carlen 2008) - an area of work where it is possible to distinguish between competence (knowing the rules and doing what is required) and performance (using the rules to achieve meaning). While a great deal has been written about the historical, political, policy and practice changes that have shaped the role of the probation officer, very little has been written on the changes to occupational cultures and the ways in which probation workers themselves view the impact of these changes. This article aims to fill that gap by exploring the meaning of 'doing probation work' from the perspective of probation workers themselves ${ }^{2}$. 
The probation service in England and Wales reached its centenary in 2007 but the response of workers to this was muted, despite the imaginative efforts of both the National Association of Probation Officers (NAPO 2007) and Senior (2008) to compile books of recollections. Mair and Burke (2011) suggest that 'a more considered response would have been to ask how it had come to this' and they liken the service to a Cinderella who 'never actually arrived at the ball' (2011:1). They draw the pessimistic conclusion that while community sentences probably have some sort of future in criminal justice policy, this may well not be the case for the probation service. That it still exists after 100 years is something for which we should be grateful, they say, but 'it has lost its roots, its traditions, its culture, its professionalism' (2011: 192). It is the aim of this article to challenge this narrative of decline. Our research (Mawby and Worrall 2011a) ${ }^{3}$ suggests that, while working in a much changed world, probation workers retain a strong sense of all these things. What Mair and Burke fail to give credit for is that modern probation workers can handle the 'imaginary'. They can do what is required of them - they can be competent offender managers - while constructing identities that allow them to believe that they are still part of an 'honourable profession' (Probation Worker $3^{4}$ ).

In Australia the term 'probation' carries less ideological baggage and appears to be almost inter-changeable with 'community corrections' (though see Harker and Worrall 
2011 for a discussion of the return to traditional terminology in Western Australia). The history of community corrections in Australia is more recent than in England and Wales (and varies between jurisdictions), having developed significantly only in the later decades of the $20^{\text {th }}$ century (Israel and Dawes 2002) ${ }^{5}$. There has been even less academic research in this area than in England and Wales. Nevertheless, the debates surrounding policy, practice, training, effectiveness and credibility have been very similar, albeit with the unique dimension of the implications of alternatives to imprisonment for the Indigenous population (Israel and Dawes 2002; Worrall 2004; Blagg 2008; Harker and Worrall 2011). As in England and Wales, very little has been written about the changes to occupational cultures and the ways in which community corrections and probation workers view themselves and their role. The most consistent body of research on the relationship between probation/ community corrections officers and offenders has been undertaken by Trotter (2006), who has concluded (among other things) that workers who prioritise 'pro-social modelling' and 'problem-solving' approaches over more punitive approaches are likely to be more effective. However, for the purposes of our argument here, research in Brisbane by Allard et al. (2003) identifies one of the key issues of our own research, namely, that community corrections workers are skilled at managing the pressures of role conflict in the work. Allard et al. challenge the received wisdom that community corrections 
workers experience stress and dissonance as a result of role ambiguity and conflict between the welfare and punishment aspects of the work, leading to occupational burnout. On the contrary, they found that most community corrections workers can reconcile these demands and that occupational burnout, where it occurs, may be related more to external organizational factors, requiring further research.

Probation workers contend with turbulent social, economic and political conditions (Davidson 1976; Mawby and Worrall 2011b) and are subjected to converging pressures from the government, management and the media. These include changes in training frameworks, roles and organizational structures, the threat of competition from private providers as part of the Conservative-Liberal government's 'rehabilitation revolution' and cuts in criminal justice agencies' budgets of $23 \%$ following the Comprehensive Spending Review of 2010. Overlaying this uncertain working climate, the dominant media discourses foreground concerns over rising prison populations, 'weak' community punishments and popular anxieties around crime and victimisation. The probation service as an organization and frontline probation workers have to find ways to respond to these 'new realities of the workplace' (Naus et al. 2007:684) if the organization is to survive and be successful and if employees' work is to be meaningful and fulfilling. 
We will argue that the responses by probation workers to these pressures can be modeled by drawing on the Hirschman's (1970) concepts of 'exit, voice, loyalty, and neglect', extended by Naus et al. (2007) to include 'organizational cynicism', by Parks et al. (2010) to include 'organizational expedience' and by us to include 'edgework' (Lyng 1990, 2005). However, before discussing and applying these concepts we will, first, provide some information on the empirical study which provided the data drawn on in this article and, secondly, we will develop the theme of criminal justice occupational cultures and, in particular, the characterization of probation work as a tainted occupation.

\section{Methodology and participants}

We used an interview-based, rather than observational, design for this study as we wished to examine how probation workers construct, and tell the stories of, their occupational identities, values and cultures. The interview sample was constructed through the authors' network of contacts and also access facilitated by the Probation Chiefs Association (PCA). The former enabled the recruitment of eight former probation workers and ten Trainee Probation Officers (through emails approved by their university lecturer). The latter endorsed the research and encouraged Chief 
Officers/CEOs to facilitate access without at any stage trying to influence the direction or outcomes of the research. As a result sixteen staff of chief officer grade agreed to be interviewed and in two probation areas we arranged for emails to be sent to the whole workforce requesting volunteers in the sample categories to contact us direct. From these responses we undertook 26 interviews. The purpose of identifying a varied sample of probation workers was to examine the extent to which a range of probation workers perceived their working lives and contribution to the criminal justice system.

In terms of gender and ethnic origins, 33 (55\%) interviewees were female and 8 (13\%) identified themselves as being Indian, Black African, Black Caribbean, Irish or mixed other. Regarding age, 26 (47\%) were under 50 years and 34 (53\%) were over 50 years. Our age profile was distorted by the high number of Chief Officers who volunteered to be interviewed. Chief Officers represent $27 \%$ of our sample. We analysed their responses separately from other grades, but found no major differences to support the existence of distinct 'management' and 'operational' cultures. Indeed the similarities were marked, possibly because all the interviewed Chief Officers were career probation workers with experience in different grades. The sample's demographic profile is not greatly different to that of the service, which is approximately $68 \%$ female, $14 \%$ Black and Minority Ethnic, and $34 \%$ over 50 years ${ }^{6}$. The length of time interviewees had worked for the probation service ranged from two years to over forty 
and many experienced workers had been employed in a range of rural and urban settings during their careers.

The interviews were divided between the authors (Mawby undertook 28 and Worrall 32) and were carried out between June 2010 and March 2011. Prior to each interview, a list of themes covered by 25 questions was sent to each participant for them to reflect on. During the interviews each participant talked about their working lives based on these questions. They talked about their original motivations and aspirations on joining the probation service, their knowledge of the service at the time of joining, their training experiences and career development, their views on public and media perceptions of probation work, their daily routines and relations with probationers, courts and other criminal justice practitioners; and they described crises and typical working days. The interviews were recorded and transcribed and the transcriptions were analysed independently by each author. These analyses were brought together to produce summary documents by category of worker, from which key themes were identified and explored. All participants were invited, along with other interested academics and practitioners, to a day conference where interim findings were presented and feedback obtained. Subsequently, a short 'everyday English' report was produced in both hard and electronic versions (Mawby and Worrall 2011a). 


\section{Cultures and criminal justice agencies}

The culture of an occupation or an organization can be described as the values shared by individuals that manifest themselves in the practices of members of that occupation or organization. According to Morgan (2006:126-38) organizational culture includes: operating norms, symbols and rituals of daily routine; language used within the group; stories and myths about individuals, the group, and the organization which sustain cultural values; the work atmosphere, including the physical environment; and shared systems of meaning that are accepted and acted upon.

It is widely accepted that all organizations have cultures and their development provides a resource which allows groups and organizations to function internally, to react and adapt to the external environment and to integrate new members into ways of working (Schein 2010). Consequently cultures can be resistant to change and an obstacle to progress or alternatively a source of stability and a force for good.

In the criminal justice arena, despite recent re-emergent interest in the cultures of prison officers (Crawley 2005; Crewe et al. 2010; Tait 2011), probation officers (Burke and Davies 2011), police auxiliaries (Dolman 2008) and private security workers 
(Button 2007; Hucklesby 2011), only police culture has been subjected to in-depth study (for recent examples, see Skolnick 2008; Loftus 2009 and Reiner 2010).

The literature on probation cultures is more limited though valuable work is ongoing ${ }^{7}$. Our research seeks to make a contribution not only to a criminological understanding of a criminal justice occupation but also to a sociological understanding of a 'socially tainted' public sector organization, regarded by some as being in terminal decline.

\section{Probation as a tainted occupation}

In seeking to characterize the occupational cultures of probation work, our starting point is Ashforth and Kreiner's (1999; 2007) concept of 'dirty work'. One of the dilemmas that emerged during our interviews was the extent to which workers felt that the social status of the probation officer had changed from that of being 'an authoritative person' (CO14) to being 'a waste of time' (PW9). The image of the probation officer as 'almost priest-like' (FPW7) has been transformed to that of someone who is doing society's dirty work and should probably be ashamed, rather than proud, of themselves, for working with the 'undeserving'. 
Ashforth and Kreiner's (1999; 2007) concept of 'dirty work' describes those occupations that society regards as 'necessary evils' - jobs that someone has to do but which are considered to be unpleasant, disgusting and/or morally questionable. People who undertake such work are attributed with a stigma or negative identity as 'dirty workers', who may be physically, socially or morally tainted. Workers who are physically tainted undertake work that is intrinsically dirty, such as rubbish collectors, butchers or embalmers, or they have to do their work in 'noxious' conditions, such as miners or dentists. Workers who are socially tainted have regular contact with stigmatized groups, for example prison guards and social workers, or are in a servile relationship with their employer or clients, for example domestic servants. Finally, workers who are morally tainted do work that is morally dubious, for example exotic dancers, or utilise unethical methods, for example debt collectors. Within this model, it is not too difficult to identify probation workers as being socially tainted. On behalf of society, they engage regularly with stigmatized people and run the risk of being stigmatized themselves. Alongside the work of other criminal justice occupations such as police, prison guards and criminal lawyers, society reluctantly accepts the necessity for probation work; as one interviewee noted, 'People just want that reassurance that there's somebody doing it' (CO4). 
Time and again in our research, however, people told us that the public really did not know what the work was about so the taint was, in their view, based on both limited knowledge or experience and in many cases, after initial curiosity, a reluctance to find out more:

People either don't want to have a conversation about it, they just don't wanna go there, or they say 'oh that must be depressing work - that's kind of dirty, depressing'. They don't wanna know about that, 'Let's talk about something happy' (CO5).

Some interviewees avoided saying much about their work in social situations with unfamiliar people. One (male) interviewee was at a party with his male partner and seemed more uncomfortable about disclosing his occupation than his sexual orientation, as his turn of phrase indicates:

There was an awkward moment....Do I come out as a probation officer? (TPO4)

One reason for the low public profile of the probation service has been its low media profile in the past; it has been 'a bit of a secret service' (CO12) and this has offered protection from the worst excesses of media criticism. But recent high profile cases, where people under probation supervision have committed murder, have changed public attitudes from benign indifference to marked negativity (Fitzgibbon 2011). 
There is nothing new about arguing that personal or occupational stigma has negative consequences, resulting in a spoiled identity (Goffman 1963). For Ashforth and Kreiner (1999), however, the research conundrum is that stigma can result in a positive identity among dirty workers:

...the real issue for dirty workers, then, is not so much 'How can they do the work?' but 'How do they retain a positive self-definition in the face of social assaults on the work they do?'

(Ashforth and Kreiner 1999:418)

Ashforth and Kreiner's $(1999 ; 2007)$ model of dirty work gives rise to a number of processes whereby dirty workers construct positive work identities. Firstly, they develop ideologies that reframe, recalibrate and refocus the purpose and value of their work. They reframe by foregrounding the virtues and benefits of the work (for example, the traditional probation motto of 'advise, assist and befriend' becomes updated to 'enforcement, rehabilitation and public protection'), recalibrate by adjusting the standards that evaluate the extent of 'dirt' (for example, massaging the statistics to demonstrate reductions in re-offending) and refocus by emphasizing the rewarding aspects of the work over the dirty ones (for example, concentrating on 'good news' stories about the offenders who have been successfully rehabilitated 
rather than the 'bad stories' of those who commit serious further offences). Secondly, dirty workers engage in social weighting tactics - not unlike Sykes and Matza's (1957) 'techniques of neutralization' - condemning those who condemn them, supporting those who support them (if any) and making selective social comparisons 'to draw more flattering inferences about themselves' (Ashforth and Kreiner 2007: 150).

We use the model of 'dirty work' to gain insight into the ways in which probation workers routinely construct and maintain for themselves a positive work identity. However, the model does not entirely explain all our data. In particular, the concept of 'dirty work', as presented by Ashforth and Kreiner assumes a stable, or relatively stable, external environment and a consistent public attitude towards the work. As indicated above, our interviewees believe that public perceptions of probation work have changed. Whether this is a symptom or a cause of the turbulent political, social and economic changes in the external context of probation work is a matter of serious debate. The concept of 'dirty work' provides us with a mezzo-level tool with which to analyse group attitudes and behaviour but it does not fully account for either macrolevel societal changes or micro-level individual responses. The former of these aspects has been expounded in numerous historical accounts of the probation service (most recently Canton 2011; Mair and Burke 2011) and it is to the latter aspect of our theoretical framework that we now turn. 


\section{Exit, Voice, Loyalty, Neglect, Cynicism and Expedience}

Hirschman's (1970) 'exit, voice, and loyalty' model has been used widely to analyse and compare employees' responses to adverse workplace conditions. He posited responses of 'exit' (employees leaving the organization or thinking seriously about doing so), 'voice' (employees expressing their concerns and dissatisfaction to management and others) and 'loyalty' (employees retaining an attachment to the organization and waiting for better times). A fourth component of 'neglect' (employees withholding effort through lax behaviour such as persistent lateness, absenteeism or poor performance) was subsequently added (Farrell 1983).

More recently, the EVLN model has been further extended. Naus et al. (2007) added a fifth dimension of 'organizational cynicism', in which employees adopt a negative attitude towards their employer based on beliefs that the organization lacks integrity. Consequently they respond negatively toward the organization and tend to disparage it (2007:689). While organizational cynicism can result in apathetic and alienated behaviour, it can also be a critical but caring voice of conscience. The sixth response of 'organizational expedience' (Parks et al. 2010) moves us more clearly into the arena of 
'rule-breaking', describing 'workers' behaviours that (1) are intended to fulfill organizationally prescribed or sanctioned objectives but that (2) knowingly involve breaking, bending or stretching organizational rules, directives, or organizationally sanctioned norms' (2010:703). Arising from the subjective experiences of role overload, emotional exhaustion, tension and/or task conflict, expedient behaviour can result in increased organizational effectiveness but may also result in 'workers attempting to "make it by faking it" - acting out their roles as if they understand expectations and doing whatever it takes to look successful, while hoping results will follow' (2010:714).

In the following section, we use our research data to illustrate these six responses, but we argue that this model alone does not entirely capture some aspects of that data. While the concept of 'organizational expedience' comes closest to providing an explanation of contemporary probation work, we suggest that there are some elements of the work that can only be explained in terms of 'voluntary risk-taking'. In an organization obsessed with risk assessment and risk management, we argue that it is not inappropriate to draw upon the sociological concept of 'edgework' (in particular 'workplace edgework') to extend our understanding. 
Fig. 1. Probation worker responses

\section{Exit}

Among our participants were those who left the service at retirement age, those who left to move into academic posts, those who were on the verge of retiring and younger workers who had decided that they were unlikely to spend many more years in the service. Those in the first category talked about careers of fulfilling work in different posts, adapting to change (giving examples of loyalty) and then, as managerialist practices dominated, experiencing a gradual wearing down and mental exiting, referring to themselves as 'dinosaurs'. FPW1 talked about the service leaving her rather than vice versa when she left in 2001 after 20 years, implying that it was the job that had changed, not her.

Those who moved to academic posts were more positive, feeling that they could retain their attachment to the service without compromising their principles or values: 
I saw too many changes. ... I thought this would be a real opportunity to get into the training and positively shape that ...I thought yeah it'd be a good opportunity (FPW4).

Those on the verge of retiring were among our most disillusioned interviewees, expressing cynicism (see below) about the organization's integrity and its treatment of experienced workers. PW8 talked about her determination to be a rebel to the end, acknowledging that she was 'difficult to manage':

I think the service will be delighted to see me go [laugh]. Hurray she's gone, thank the Lord for that [laugh].

But there were younger workers, even trainees, who were already thinking about their exit if things did not improve:

I think, for the next few years, I'm happy to be a probation officer and get the experience. Depending on how much further the organization changes, especially in terms of how you work with offenders, I'm not sure how it's gonna change. If it changes in a way that I don't.... I can't work with or I don't like the working style, then I might leave and look for something else (TPO1). 


\section{Voice}

The absence of 'voice' at every level within the organization was one of the most frequent complaints we heard in interviews. The greatest concern among Chief Officers was the absence of any significant probation voice at the highest level within the National Offender Management Service (NOMS). There was a widespread view that NOMS was prison-dominated and that the consequent organizational culture was one of 'command and control' (CO2), with probation being regarded as 'troublesome' because it 'wouldn't do what it was told' (CO14).

PW10 became very emotional when asked about her view of herself as an experienced worker within the organization. 'I would really like this noted down', she said:

...so de-professionalized, demoralized... told how to think, told how to feel. Very, very unhappy towards the end of my career, professionally, very unhappy. Very, very unhappy. I haven't left though, but very unhappy.

Some participants found their voice through union membership. Interviewees who were probation workers in the 1970s and 1980s remember NAPO (National Association of Probation Officers) as being a powerful influence on probation cultures, providing an alternative and critical vision of the service. Branch meetings and national conferences were significant networking sites and allowed for debate that was at 
times both intellectual and stimulating - an opportunity to get away from the demands of the daily routine. As CO14 put it, 'the people I wanted to respect me were other NAPO members, not my managers necessarily - you got your cred from NAPO.'

Most experienced workers that we interviewed were members of NAPO and those who remained active were clearly committed, believing that, despite being a small union, NAPO 'punches above its weight' (PW7). But the influence of NAPO has declined and some workers have turned to the larger public sector general workers' union, UNISON, in the hope of finding a 'voice':

I'm gonna effect some change. I don't know at what level and where, but that's why I'm in the union, I suppose, when you're an elected representative, your voice needs.... your voice has got to be heard. They don't need to take your advice but they certainly need to hear you. And that's what I like about the union role I've got - they're not able to dismiss me (PW20).

\section{Loyalty}

Most of our participants were, by definition, displaying loyalty by remaining in the organization and, by and large, speaking very positively about their work with 
offenders. Even those who disliked the general direction of change were finding ways to cope, survive and achieve job satisfaction. They were drawn to the job through common values which include: a belief in the possibility of change and their own ability to effect it (to 'make a difference'); a faith in both offenders and colleagues which may be, but more often is not, a religious faith; and an ethos of service or vocationalism (that the work is a 'calling').

The 'loyalists', even the cynics and world-weary workers, regard probation as more than just a job; they need to make sense of why they do probation work. They need to do meaningful work and the cultural locators or filters for this include: an intellectualism that values thinking and reflection; a commitment to social equality and a respect for social diversity; a political positioning that historically has been overtly left-leaning (though is less so currently); and a protective stance on the threatened 'domain', or traditionally recognized field of expertise (Davidson 1976), of probation work. They construct themselves as professionals with a legitimate desire to be autonomous (though that desire is often perceived to be thwarted by the organization). They draw on an institutional memory that values a golden age of probation when workers were autonomous, (while at the same time acknowledging that not all autonomous practice was best practice). As we shall see below, they also construct for themselves moments of action when they are called upon to test out 
their professional skills in situations that are potentially chaotic or dangerous and introduce into their work a creativity (or departure from the script) that they believe the organization prohibits (but which the organization is implicitly dependent on).

Some probation workers joined the organization only to find that aspects of their personality or part of their set of values were not sufficiently attuned to the dominant organizational values and ethos. However, they demonstrated loyalty through being prepared to adapt and change:

Where I did have problems was in terms of me fitting into the organization as a young man especially, you know, and a bit of a going out sort of lad and partying. I'm a bit boisterous and I've got a big voice, so I stand out and I make a target for myself, so you know what I mean, I had a few complaints that people said, you know, he's a bit loud, a bit this, a bit that, a bit.... came across a bit even sexist at some times. So you know, I had a lot of self-reflection to do (PW15).

Others were happy to enforce the new ways of doing things:

This guy [an offender], he had probation officers way back.... he's like 40 -odd.... and he used to come to me and say, 'you're very different from the people I used to have, you know, they used to let me just do what I want' ... I said you 
need to understand it's changed. You know, like two misses and you're in breach, and you go back to court. So that is changing; that's fine with me (TPO10).

In general the trainee probation officers had an optimistic spirit, a loyalty towards the organization. Certainly they were worried about the caseloads they would face, the long hours and difficult cases, but there was an acceptance that this was the organization they joined and they were learning, adapting, experiencing some highs and lows, aspiring towards specializing or climbing the hierarchy. They lacked cynicism, they valued humour and some had spotted that probation workers can be moaners.

\section{Neglect}

We did not hear many stories about the withholding of effort. However disillusioned our participants might have been with the organization, they saw themselves as having a higher loyalty to offenders. They would work long hours and endure the tedium of spending 70 per cent of their time in front of computers if they could justify it as being in the interests of their 'clients', as many still insisted on calling offenders. Withholding effort took two predominant forms: taking sick leave and abusing 
professional autonomy. The former was explained as a mechanism for coping with stress:

Yeah, and some people, they just.... it's.... they just take sick leave or just, you know, it's like you're tired out, it's like you can't give any more [laugh] (TPO3).

The latter was something that happened in the 'good old/ bad old days':

I think collectively, we kidded ourselves before about 2001, how good we were at that core task. I think there were some very, very skilled and experienced practitioners, who did it very well, and would be perfectly at home actually in the modern probation service. Do I believe the vast majority of probation practice met those high standards? Do I hell. It was a million miles away. People kidded themselves. I remember having arguments in, you know, the early 2000s, with probation colleagues, who argued that actually seeing someone once a fortnight or once every three weeks, for half an hour, really had an impact on offending behaviour. It was nonsense. We were kidding ourselves (CO1).

\section{Organizational cynicism}


While some interviewees were undoubtedly cynical about the organization and 'management', they would also emphasize that they were doing things their own way to counter perceived lapses in organizational integrity:

I think it becomes more and more difficult. But I think certainly, if I didn't have the experience I've got, and the fact that I'm not particularly scared of, you know.... I'm old enough now [laugh], I'm not scared of huge organizations like probation or whatever, because I know that I do my job (TPO8).

Another experienced worker was furious that she had been disciplined for attending the funeral of an offender's mother. She was told that she should have sought permission first:

Do I go and ask can I go to the funeral, to be told no, you can't? Do I go and ask can I go to the funeral, to be told yes you can but we must accompany you? Do I not go to the funeral? Or do I go to the funeral and just make sure that nobody knows about it and hope that I don't get found it? What sort of a dilemma is that for a professional person? I'm nearly 60 years of age, I have to go and ask permission (PW10). 


\section{Organizational expedience}

What appeared to have dawned on some workers was that it no longer matters what you do, provided the appearance of how you do it meets organizational requirements. The completion of risk assessment reports was regarded by the organization as being more important than their content and the meeting of breach proceeding targets more important than working with an offender to avoid breach proceedings. For some interviewees, this resulted in an undermining of their sense of professional integrity:

I want to do good work but l've been told that I must try to be comfortable with 'good enough' work. When I was a TPO, my friend and I used to spend ages discussing and planning our work with offenders but no-one noticed us. But we had another friend that everyone thought was wonderful. She said 'I've learned that no-one is interested in offenders, they're just interested in OASys ${ }^{8}$, so I make sure my OASys forms are immaculate (PW2).

But for others, the challenge of reconciling the meeting of organizational objectives with carrying out meaningful work with offenders was motivating in itself. We heard many stories of workers who took pride in bending or even resisting the rules in order to work effectively, while avoiding organizational censure: 
So you can be creative because the way I see it, when I'm in that room, nobody knows what I'm doing. They know what.... they think they know what I'm doing and I tell them what I'm doing when I write it on the computer (PW15).

Much of our research data can be adequately analyzed in terms of 'loyalty' and 'expedience', with pockets of 'exit', 'neglect' and 'cynicism', and a somewhat alarming absence of 'voice'. Nevertheless, there remains data that cannot be captured within this framework. In the next section we argue that some elements of probation work can only be understood as examples of 'edgework'.

\section{Edgework in probation}

Probation workers may not generally be regarded as obvious edgeworkers, but our research suggests that it is possible to identify elements of edgework in some probation work and that it is only by acknowledging this that we can obtain a complete picture of what it means to be a probation worker in an uncertain and potentially uncontrollable environment. Edgework refers to activities that involve voluntary risktaking, where there is a 'clearly observable threat to one's physical or mental wellbeing or one's sense of an ordered existence' (Lyng 1990:857). It is most easily illustrated in dangerous pastimes such as sky-diving, solo rock climbing or even 
criminal behaviour, but the 'edge' can be any boundary where the actor, potentially, can lose control and harm themselves. Controlling this boundary involves the deployment of a specific skill 'to maintain control over a situation that verges on complete chaos, a situation most people would regard as entirely uncontrollable' (Lyng 1990:859). Edgework tests this skill by getting as close as possible to the edge without crossing it but it is not gambling, recklessness or the result of a psychological predisposition to take risks (Lyng 2009: 120).

There is a structural context to edgework, which is both a form of escape from (or resistance to) the rules and routines of contemporary life (Ferrell 2005; Katz 1988) and an implicit requirement imposed by organizations that displace their collective responsibility for risk management on to individual employees through a mechanism of responsibilization (Lyng 2009: 106). Edgework is the great 'unspoken'. Paradoxically, therefore, workers are both freeing themselves from, and better integrating themselves into, modern working conditions when they pursue edgework (Lyng 2005). Edgework is also a gendered concept. Just as Goffman concedes that 'action...seems to belong to the cult of masculinity' (1967: 156), so, traditionally, edgework relates to male-dominated activities and assumes the subjective sensations of the masculine mind and body. Increasingly women are engaging in the same activities, although their experience of the risk-taking is different, involving different emotional management 
(Lois 2005). Perhaps more significantly, as the definition of edgework has developed, it has increasingly embraced the experiences of women's routine lives, both at home (see Rajah, 2007 on edgework in violent intimate relationships) and, as we argue here, in the workplace.

Many probation workers in England and Wales spend the majority of their time in front of computers in open-plan offices, undertaking important but routine risk assessment and risk management (Mawby and Worrall 2011a). The rest of their time is spent interviewing offenders in the security-conscious environment of anonymous public sector offices frequently located on industrial estates or technology parks and away from the places where offenders live. The work is demanding and the consequences of making mistakes could be serious but opportunities for 'action' are very few. Yet probation work is as much about controlling the boundaries between order and chaos as is police work, albeit on a smaller and more specific scale. Many of our respondents expressed the desire for 'action' and 'autonomy'. This was emphatically not about behaving recklessly or disregarding the organization's objectives. Nor was it necessarily about a nostalgic return to a mythical golden age of probation. Rather it was about putting their skills to the test 'on the edge'. 
We suggest that (some) probation workers engage in edgework. This is partly because, as Lyng (2005:25) argues, in occupational settings risk taking 'has held an attraction for increasing numbers of people in late capitalism' and, significantly, because edgework is 'increasingly what institutions expect of many people' (Simon 2005: 206). Edgework is an identifiable, though rarely acknowledged, part of the workplace. Here we identify four possible aspects of probation edgework.

First, liking offenders and vicarious rule-breaking: the lure of notoriety: Probation edgeworkers enjoy controlling the boundary between getting close to offenders (establishing rapport, showing empathy and concern and so on), in order to do effective work, and maintaining distance or behaving 'professionally' towards someone who has broken the law and is disapproved of. This involves actively choosing to like offenders:

I think offenders are great. We still have some probation officers who don't like offenders. I really worry about that. At induction I say to people...if you're meeting offenders, like them for goodness sake, because if you don't like them, this will be a miserable job and you'll be scared of them and they'll know (CO15). 
Taking a step further towards the 'edge' were those probation workers who suggested that it was not only offenders that they found attractive, but offending itself. Drawn towards behaviour regarded as deviant or 'other', they control this through working with offenders while not crossing the boundary into illegality themselves:

What is it about people who break the rules that is the appealing thing that brings probation officers together? I think, for me, I'm not a person who breaks the rules...I've got a super-ego the size of Jupiter. So I do my rulebreaking vicariously (FPW1).

Second, danger and the threat of violence: the sensation of omnipotence: Although they are not expected to 'put themselves in harm's way' in the same way as police or prison officers, probation workers are often in the position of negotiating the boundary between controlling a 'risky' offender and the situation getting out of hand, resulting in violence, harm or loss of professional face:

When I was under threat ... your skills carried you through. You learnt... how to read people and when it was right to confront and when it was right to sort of just be a bit more conciliatory. You very much relied on those ... skills to manage some very difficult individuals (CO12). 
Third, fast and exciting: performing probation: We had not anticipated that even the most committed probation worker would describe their work as 'exciting', but a number did. Some probation workers appear to get a kick out of being on their metal, using their skills to control a situation that could fall apart if they mess up:

I think I'm attracted to 'fast and exciting'... I've had emergency things happen, like emergency recalls to custody. Or the magistrate wants that oral report done in 20 minutes and you've only just finished interviewing the offender, and you gotta think on your feet and you've gotta stand up in court and deliver that assessment in 20 minutes. I like that (TPO4).

Fourth, creativity and intensity of work: the ambiguity of innovation: In situations that verge on chaos, where things might just fall apart, professional skills are tested to keep things together. The work may be intensive, there may be a need for creativity and it requires intellectual and emotional investment. Through taking risks and being creative, probation workers regain agency and achieve feelings of authenticity and self-actualization. They are being true to themselves and their occupation and 'making 
a difference', realising some of the motivations and hopes that led them into the career in the first place:

I've got guys who kind of.... who don't like conforming in a room, particularly people like just out of prison, they don't like being sat in an interview room. I'd much prefer to be able to get them out, you know, and actually you have a walk with them (PW17).

These examples illustrate how edgework can be exhilarating and empowering, but probation workers live in fear of 'getting it wrong', of miscalculating the risk of an offender re-offending, either in terms of frequency or, more significantly, in terms of the harm done. It is the spectre of the 'serious further offence' (SFO) that inhibits routine voluntary risk-taking by probation workers. In situations where offenders under supervision commit murder or serious sexual assault, the repercussions for practitioners who have not followed risk assessment procedures to the letter may be dire (Fitzgibbon 2011), despite the paradox that 'only a willingness to work outside the tick-box methods and grasp the "situational context" in which...offenders are located, enables reliable estimates of real risk' (2011:144). 


\section{Conclusion}

In this article, we have sought to challenge the view that the probation service in England and Wales is an organization in irredeemable decline (Mair and Burke 2011). We have not disputed that it is struggling to contend with turbulent social, economic and political conditions that threaten its 'domain' (Davidson 1976). Nor have we disputed that it is regarded by the media and the public more generally as a socially tainted occupation, but we have argued that there is a general, if implicit, acknowledgement that 'dirty work' is necessary work and that those who undertake such work are not to be wholly denigrated.

More significantly, we have argued that probation workers respond to adverse conditions in a variety of ways and that not all of these ways are negative, passive or fatalistic. Building on the extension of Hirschman's model of exit, voice and loyalty (which now includes neglect, cynicism and expedience), we have proposed the addition of 'workplace edgework'.

We believe that we have identified a need to recognise, encourage and support the desire of workers for 'action'. Like other criminal justice occupations, probation workers find ways of 'easing' (Cain 1973) or coping with the pressures and tedium of routine work, but one of these ways is being innovative or working 'on the edge'. This 
is emphatically not about behaving recklessly or disregarding the organization's objectives. Nor is it merely about a nostalgic return to a largely mythical golden age of probation when workers enjoyed unfettered autonomy and professional discretion. Rather, it is about putting their skills to the test for the good of the offender, victims, the public and the organization. We have no wish to romanticize risk-taking or its consequences but our research suggests that at a time when the dominant discourse of offender management and community corrections emphasizes risk assessment and management, a degree of edgework is essential for both the morale of workers and the health of the service as a whole.

\section{Acknowledgements}

We would like to record our thanks to: the sixty participants who shared with us their experiences of doing probation work; the Probation Chiefs Association of England and Wales; the anonymous reviewers whose helpful comments have strengthened the article.

\section{Funding Acknowledgement}


This work was supported by the UK Economic and Social Research Council [Grant number: RES-000-22-3979].

\section{References}

Allard, T.J., Wortley, R.K. \& Stewart, A.L. (2003) ‘Role conflict in community corrections', Psychology, Crime and Law, 9, 3: 279-89.

Ashforth, B.E. \& Kreiner, G.E. (1999) "'How can you do it?" Dirty work and the challenge of constructing a positive identity', Academy of Management Journal, 24, 3: 413--34. 
Ashforth, B.E., Kreiner, G.E., Clark, M.A. \& Fugate, M. (2007) ‘Normalizing dirty work: managerial tactics for countering occupational taint', Academy of Management Journal, 50,1: 149--74.

Australian Government Productivity Commission (2012) Report on Government Services 2011, Canberra: Australian Government, Chapter 8 (www.pc.gov.au/gsp/rogs/2011 accessed 24 May 2012).

Blagg, H. (2008) Crime, Aboriginality and the decolonization of justice, Sydney, Hawkins Press.

Burke, L. and Davies, K. (2011) 'Introducing the special edition on occupational culture and skills in probation practice', European Journal of Probation, 3,3: 1-14.

Button, M. (2007) Security Officers and Policing: Powers, Culture and Control in the Governance of Private Space, Aldershot: Ashgate.

Cain, M. (1973) Society and the Policeman's Role, London: Routledge.

Canton, R. (2011) Probation: Working with Offenders, Abingdon: Routledge.

Carlen, P. (ed)(2008) Imaginary Penalities, Cullompton: Willan Publishing.

Crawley, E. (2005) Doing Prison Work, Cullompton: Willan Publishing.

Crewe, B., Liebling, A. \& Hulley, S. (2010) 'Staff culture, use of authority and prisoner quality of life in public and private sector prisons', Australian and New Zealand Journal of Criminology, 44, 1: 94-115. 
Daley, D. \& Lane, R. (1999) 'Actuarially based, online risk assessment in Western Australia', Probation Journal, 46, 3: 164-70.

Davidson, S. (1976) 'Planning and coordination of social services in multiorganisational contexts', Social Services Review 50: 117-37.

Dolman, F. (2008) Community Support Officers, their Occupational Culture and the Development of Reassurance Policing, European Society of Criminology Conference paper. Edinburgh University.

Farrell, D. (1983) 'Exit, voice, loyalty, and neglect as responses to job dissatisfaction: A multidimensional scaling study', Academy of Management Journal, 26, 4: 596607.

Ferrell, J. (2005) 'The only possible adventure: edgework and anarchy' in S. Lyng (ed) Edgwork:The Sociology of Risk-Taking, London: Routledge, 75--88.

Fitzgibbon, W. (2011) Probation and Social Work on Trial: Violent Offenders and Child Abusers, Basingstoke: Palgrave Macmillan.

Goffman, E. (1963) Stigma: Notes on the Management of Spoiled Identity, Englewood Cliffs, NJ: Prentice-Hall. (1969) Where the Action Is, London: Penguin Press.

Hamai, F., Ville, R., Harris, R., Hough, M. \& Zveckic, U. (eds) (1995) Probation Round the World, London: Routledge 
Harker, H. \& Worrall, A. (2011) 'From "community corrections" to "probation and parole" in Western Australia', Probation Journal, 58, 4: 364-71.

Hirschman, A. O. (1970) Exit, Voice and Loyalty: Responses to Decline in Firms, Organizations and States, Cambridge, MA: Harvard University Press.

Hucklesby, A. (2011) 'The working life of electronic monitoring officers', Criminology and Criminal Justice, 11, 1: 59-76.

Israel, M. \& Dawes, J. (2002) 'Something from nothing: shifting credibility in community correctional programmes in Australia', Australian and New Zealand Journal of Criminology, 2, 1: 5-25.

Katz, J. (1988) Seductions of crime: the moral and sensual attractions of doing evil, New York: Basic Books.

Loftus, B. (2009) Police Culture in a Changing World, Oxford: Oxford University Press. Lois, J. (2005) 'Gender and emotion management in the stages of edgework' in S. Lyng (ed) Edgework: The Sociology of Risk-Taking, London: Routledge, 117--52.

Lyng, S. (1990) 'Edgework: a social psychological analysis of voluntary risk taking', The American Journal of Sociology, 95, 4: 851--86.

Lyng, S. (2005) 'Sociology at the edge: social theory and voluntary risk taking' in S. Lyng (ed) Edgework: The Sociology of Risk-Taking, London: Routledge, 17--49. 
Lyng, S. (2009) 'Edgework, risk, and uncertainty', in J.O.Zinn (ed) Social Theories of Risk and Uncertainty: An Introduction, Oxford: Blackwell Publishing Ltd., 106--37.

Mair, G. \& Burke, L. (2011) Redemption, Rehabilitation and Risk Management: A History of Probation, Abingdon: Routledge.

McLean Parks, J., Ma, L., and Gallagher, D.G. (2010) 'Elasticity in the "rules" of the game: exploring organizational expedience', Human Relations, 63, 5: 701--30. NAPO (2007) Changing Lives: An Oral History of Probation, London: NAPO.

Mawby, R.C. and Worrall, A. (2011a) Probation Workers and their Occupational Cultures, Leicester: University of Leicester. (2011b) "'They were very threatening about do-gooding bastards": Probation's changing relationships with the police and prison services in England and Wales', European Journal of Probation, 3, 3: 78--94. Morgan, G. (2006) Images of Organization, London: Sage.

Naus, F., van Iterson, A., and Roe, R. (2007) 'Organizational cynicism: extending the exit, voice, loyalty, and neglect model of employees' responses to adverse conditions in the workplace', Human Relations, 60, 5: 683--718.

Rajah, V. (2007) 'Resistance as edgework in violent intimate relationships of druginvolved women', British Journal of Criminology, 47, 2: 196--215.

Reiner, R. (2010) The Politics of the Police, $4^{\text {th }}$ Edition, Oxford: Oxford University Press. 
Schein, E. (2010) Organizational Culture and Leadership, $4^{\text {th }}$ Edition, San Francisco: Jossey-Bass.

Senior, P. (2008) Moments in Probation, Crayford: Shaw and Sons.

Simon, J. (2005) 'Edgework and insurance in risk societies: some notes on Victorian lawyers and mountaineers' in S. Lyng (ed) Edgework: The Sociology of RiskTaking, London: Routledge, 203--26.

Skolnick, J. (2008) 'Enduring issues of police culture and demographics', Policing and Society, 18, 1: 35-45.

Sykes, G. and Matza, D. (1957) 'Techniques of neutralization', American Sociological Review, 22: 664-70.

Tait, S. (2011) 'A typology of prison officer approaches to care', European Journal of Criminology, 8, 6: 440-54.

Trotter, C. (2006) Working with involuntary clients: a guide to practice, $2^{\text {nd }}$ edition, London, Sage.

Worrall, A. (1998) 'Laws and orders: public protection and social exclusion in England and Wales', Current Issues in Criminal Justice, 10, 2: 183-96. (2004) 'What works and the globalisation of punishment talk' in G. Mair (ed) What matters in probation, Cullompton: Willan Publishing, 327-45. 
(2008) 'The "seemingness" of the "seamless management" of offenders' in P.

Carlen (ed) Imaginary Penalities, Cullompton: Willan Publishing, 113--34.

\footnotetext{
${ }^{1}$ In 2004, the probation and prison services joined to become the National Offender Management Service and frontline workers are generically known as 'offender managers'.

${ }^{2}$ We use the term 'probation workers' because our research participants were drawn from all grades within the organization, not just the 'probation officer' grade.

3 'Probation workers and their occupational cultures' ESRC RES-000-22-3979

${ }^{4}$ Probation Workers are hereafter abbreviated to PW, Chief Officers to CO, Former Probation Workers to FPW and Trainee Probation Workers to TPO.

${ }^{5}$ We acknowledge that the history and present role of probation and community corrections in Australia are not only different from England and Wales but also vary between States (Australian Government 2012). Nevertheless, there is a tradition in Australia of engaging with comparative research in this area (Hamai et al. 1995; Daley and Lane 1999; Harker and Worrall 2011) and we argue that some of the occupational cultural issues that are coming to the fore in England and Wales may resonate in Australia, stimulating further debate and comparative research.
}

\footnotetext{
${ }^{6}$ Response to Freedom of Information request from Ministry of Justice.

${ }^{7}$ The September 2011 special issue of the European Journal of Probation (volume 3, number 3) edited by Lol Burke and Keith Davies on occupational culture and skills in probation practice draws together some important recent work on probation cultures.
}

vii Computerised risk assessment tool predominant in probation and prison service practice. 